\title{
The effectiveness of a standardized rose hip powder, containing seeds and shells of Rosa canina, on cell longevity, skin wrinkles, moisture, and elasticity
}

\section{Phetcharat ${ }^{1,2}$ \\ K Wongsuphasawat ${ }^{1,2}$ \\ $\mathrm{K}$ Winther ${ }^{3}$}

'School of Antiaging and Regenerative Medicine, Mae Fah University, Bangkok, Thailand; ${ }^{2}$ Department of Anti-aging and Regenerative Medicine, Mae Fah University, Bangkok, Thailand; ${ }^{3}$ Institute for Nutrition, Exercise and Sports, University of Copenhagen, Frederiksberg C, Denmark

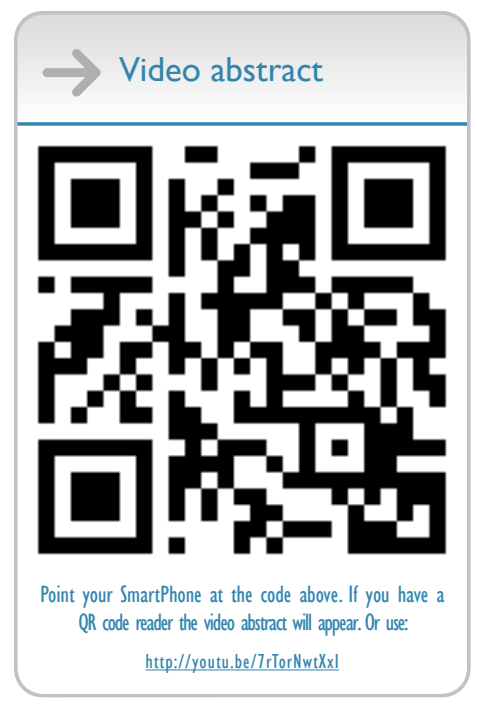

Correspondence: K Winther Institute for Nutrition, Exercise and Sports, University of Copenhagen, Rolighedsvej 26, DK-1958 Frederiksberg C, Denmark

Tel +4531333067

Email kaha@nexs.ku.dk
This article was published in the following Dove Press journal:

Clinical Interventions in Aging

19 November 2015

Number of times this article has been viewed

Objective: To evaluate the effects of a rose hip powder $\left(\right.$ Hyben Vital $\left.{ }^{\circledR}\right)$ made from seeds and shells on cell senescence, skin wrinkling, and aging.

Methods: A total of 34 healthy subjects, aged 35-65 years, with wrinkles on the face (crow'sfeet) were subjected to a randomized and double-blinded clinical study of the effects of the rose hip powder, as compared to astaxanthin, a well-known remedy against wrinkles. During the 8-week study, half of the participants ingested the standardized rose hip product, while the other half ingested astaxanthin. Objective measurements of facial wrinkles, skin moisture, and elasticity were made by using Visioscan, Corneometer, and Cutometer at the beginning of the study, after 4 weeks, and after 8 weeks. Evaluation of participant satisfaction of both supplements was assessed using questionnaires. In addition, the effect of the rose hip preparation on cell longevity was measured in terms of leakage of hemoglobin through red cell membranes (hemolytic index) in blood samples kept in a blood bank for 5 weeks. Significance of all values was attained with $P \leq 0.05$.

Results: In the double-blinded study, the rose hip group showed statistically significant improvements in crow's-feet wrinkles $(P<0.05)$, skin moisture $(P<0.05)$, and elasticity $(P<0.05)$ after 8 weeks of treatment. A similar improvement was observed for astaxanthin, with $P$-values 0.05 , 0.001 , and 0.05 . Likewise, both groups expressed equal satisfaction with the results obtained in their self-assessment. The rose hip powder further resulted in increased cell longevity of erythrocyte cells during storage for 5 weeks in a blood bank.

Conclusion: Results suggest that intake of the standardized rose hip powder (Hyben Vital ${ }^{\circledR}$ ) improves aging-induced skin conditions. The apparent stabilizing effects of the rose hip product on cell membranes of stored erythrocyte cells observed in this study may contribute to improve the cell longevity and obstructing skin aging.

Keywords: rose hip seed and shell powder, cell longevity, wrinkles, aging skin, moisture, elasticity

\section{Introduction}

Longevity of cell membranes is essential to avoid changes related to aging. This also includes aging of the skin. In this context, genetics, nutrition, and the environment are important. Another important factor is exposure to UV radiation. Exposure of the skin to UV induces the generation of reactive oxygen species, causing chronic inflammation and the breakdown of cell membranes in a process referred to as photoaging of the skin. Photoaging damages collagen, elastin, and the skin's moisture barrier, leading to wrinkles, sagging, toughening, and dry skin texture. ${ }^{1,2}$ 
Rose hips, the red fleshy berries of the dog rose (Rosa canina), have been known to have medicinal properties since the time of Pliny the Elder (23-79 BC). Botanically speaking, rose hips are the "pseudo fruits" of $R$. canina, though often alluded to as actual "fruits" in medicinal literature. Rose hips are particularly rich in vitamin $\mathrm{C}$, carotenoids, polyphenols, and various flavonoids that have potent antioxidant activity. ${ }^{3-5}$ The seeds contained within the rose hips have been shown to comprise high amounts of polyunsaturated fatty acids (PUFA), known to be essential to the skin. ${ }^{6,7}$ In addition, it has been established that the rose hip preparation tested in this study contains a galactolipid - $\mathrm{GOPO}^{\circledR}$, which has strong anti-inflammatory and antioxidant properties that stimulate the synthesis and restoration of collagen. ${ }^{8,9}$ The same standardized rose hip powder was also shown to be effective in reducing arthritis inflammation and associated pain, as well as lower inflammatory markers. ${ }^{10-12}$ Due to the composition of said rose hip preparation, the remedy may be helpful to promote longevity of cell membranes ${ }^{13}$ and promote healthy skin. ${ }^{6}$ Methanolic extract from rose hip has previously been shown to be an inhibitor of melanogenesis, and the plant has been suggested as a skin pigmentation prevention agent when taken orally. ${ }^{4,14,15}$

This study is therefore aimed at investigating the effects of a standardized rose hip powder (Hyben Vital ${ }^{\circledR}$ ) containing equal amounts (1:1 in volume) of $R$. canina seeds and shells (red pseudo fruit flesh) on markings of aging in skin cells. The impact on the skin (if any) was compared to the wellknown impacts from astaxanthin, a powerful antioxidant, ${ }^{16}$ known to improve skin condition in all layers, including the corneocyte layer, epidermis, basal layer, and dermis in both sexes. ${ }^{17}$ In addition, we examined the effect of the standardized rose hip powder on the longevity of erythrocyte cell membranes. Erythrocyte cells are good membrane models for this type of study because it can be easily detected when hemoglobin leaks out during membrane disintegration.

\section{Methods}

\section{Study design and patients}

1) To test if the rose hip powder, given orally, would have any impact on crow's-feet wrinkles, skin moisture, and elasticity as compared to what was observed for patients treated orally, for 8 weeks, with astaxanthin, a wellknown antiwrinkle remedy.

2) To estimate the effectiveness of the rose hip powder on cell longevity, evaluated as the leak of hemoglobin from red cells drawn from volunteers previously treated with rose hip for 4 weeks.

\section{Methods \\ Design of studies}

The study on the effect of rose hip as compared to astaxanthin on skin wrinkles was a randomized, double-blinded controlled clinical trial. Measurements for crow's-feet wrinkles, moisture content of the skin, and skin elasticity were performed during clinic visits at the beginning of the study, after 4 weeks and after 8 weeks of supplementation (Figure 1).

The study was approved by the Ethical Committee of Mae Fah University, Bangkok, Thailand, and all patients gave their consent. Before conducting each measurement, the subject's face was washed, and he/she was allowed to sit and rest for 20 minutes in a controlled test room environment that was maintained at $25^{\circ} \mathrm{C}$. Participants' satisfaction and adverse reactions experienced from using the supplements were also assessed at the end of the study.

The study on red cell longevity was an open study, based on determining the differences in plasma hemoglobin leakage and hemolytic index, in blood samples collected from rose hip treated as compared with untreated individuals. Blood samples were taken from a cubital vein pretreatment, after 5 days, 14 days, 21 days, and 28 days of treatment, and finally 5 weeks after cessation of therapy. Generally, the blood samples were collected in test tubes containing $3.13 \%$ citrate and stored in a blood bank up to 63 days at $4^{\circ} \mathrm{C}$. At each sampling, six samples were taken, so there was a sample for each time point for determination of hemoglobin leakage and hemolytic index.

\section{Subjects}

For the double-blinded comparative study of the effect of rose hip as compared to astaxanthin on skin wrinkles, 34 healthy

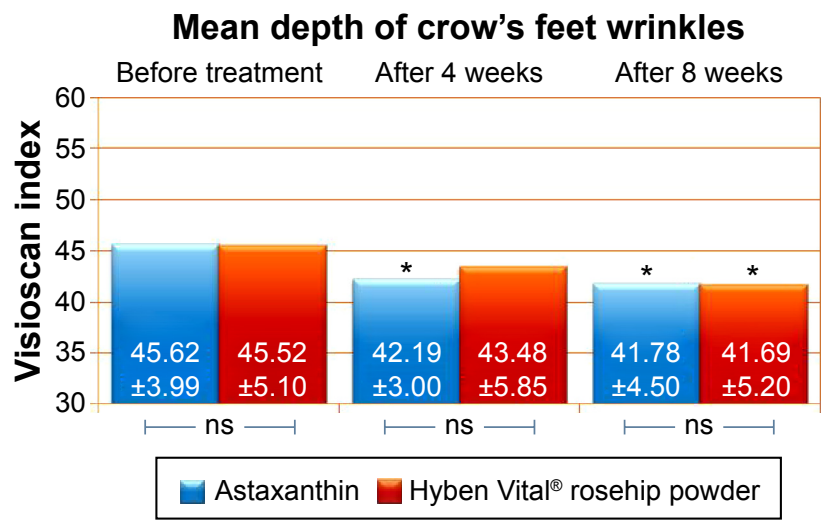

Figure I Mean depth of crow's-feet wrinkles are given for rose hip powder and for astaxanthin.

Note: $* P<0.05$ vs before.

Abbreviation: ns, not significant at $P>0.05$. 
male and female volunteers were recruited with a mean age of 44.5 years, range: $35-65$, who responded to local announcements and who appeared to have well-defined crow's-feet wrinkles or possibly other well-defined wrinkles on the face. Major exclusion criteria were smoking, being pregnant or breastfeeding, or having history of taking derivatives of vitamin A within 3 months before study. Volunteers on botulinum toxin, collagen, or fillers injection within 12 months before the study were also excluded. Furthermore, volunteers using facial products containing hydroquinone, steroids, or other creams to reduce wrinkles on the face or who took vitamin supplements of various kinds within the period of $<4$ weeks prior to the study were also excluded from the study.

For the study of the effect of rose hip on red blood cell longevity, 18 healthy volunteers represented by both sexes, mean age 47 years, range: $30-59$ years, were included in the study as the test group, after local announcements. A group of six volunteers not receiving any rose hip, astaxanthin, vitamins, or food additionals were included as a control group. All volunteers were free from any known diseases and were not on vitamin or food supplementations for at least 3 months before entering the study. They were also asked to refrain from taking any other vitamin supplementation during the entire study period that was 28 days of treatment, followed by 5 weeks of follow-up. In this study on red cells, six controls, who were not receiving treatment, were included to serve as controls during the described time period.

\section{Investigational medicines}

For the comparative study of the effects of rose hip compared to astaxanthin on the skin, six capsules containing either a total amount of $3 \mathrm{~g}$ of FDA approved dietary supplement rose hip powder (trade name: Hyben Vital/Hi-flex ${ }^{\circledR}$ rose hip powder) with seeds and shells or similar amount of capsules containing a total amount of $4 \mathrm{mg}$ astaxanthin was supplied.

The rose hip powder is prepared from a selected subtype of $R$. canina L. by name Lito. The Plant Variety Office has acknowledged the grant of community plant variety right by its decision No: EU 21641 of the January 14, 2008. The Lito plant contains high amounts of galactolipid (GOPO). ${ }^{8}$ The product is dried at low temperature using a patented methodology, and the powder always contain a minimum of GOPO of $150 \mathrm{mg} / \mathrm{kg}$ when leaving the production facilities at Langeland, Denmark. The astaxanthin in capsule (trade name: Astawell ${ }^{\circledR}$ ) contained Haematococcus pluvialis, microalgae, and rice bran oil. Capsules were of identical appearance and size and taken at three in the morning and another at three in the evening for the 8-week long study period.

For the study on the effects of rose hip powder on cell longevity, plastic bottles with $250 \mathrm{~g}$ of rose hip powder containing seeds and shells were delivered by Hyben Vital International, Langeland, Denmark, directly to the study subjects. The product was dried using a patented methodology. Here, 45 gram was administered daily, at noon, as a part of the daily lunch packet added to yoghurt.

\section{Measurement parameters}

1. Fine lines and crow's-feet wrinkles were measured by using Visioscan ${ }^{\circledR}$ VC 98 (Courage+Khazaka electronic $\mathrm{GmbH}$, Cologne, Germany).

2. Moisture content of the forehead was measured by using Corneometer $^{\circledR}$ CM 825 (Courage+Khazaka electronic $\mathrm{GmbH}$, Cologne, Germany).

3. Elasticity of right cheek was measured by using the Cutometer $^{\circledR}$ MPA 580 (Courage+Khazaka electronic $\mathrm{GmbH}$, Cologne, Germany).

4. Patients' evaluation of their skin (questionnaires).

5. Researchers blinded evaluation of photos of the skin during the 8-week treatment period.

6. Plasma hemoglobin leakage and hemolytic index.

For the studies on red blood cell longevity, blood samples stored for 10 days were taken out, stressed by gentle shaking in a water bath at $21^{\circ} \mathrm{C}$ for 24 hours, and then subjected to a Cobas FARA. This instrument is analyzing a spectrum of clinical chemical analysis including serum enzymes, blood glucose, and hemoglobin. ${ }^{18}$ This methodology allowed direct measurements of hemoglobin content in the medium outside the erythrocytes. In a parallel setup, the hemolytic index was also determined for each sample using Hitachi 737. This instrument is also a routine analyzer and measures electrolytes, creatine kinase, and cholesterol fractions and can also measure the amount of hemoglobin released into the medium as a hemolytic index. ${ }^{19}$ In this methodology, samples are diluted to different levels with saline and measured. Both methodologies are based on photometry using six different wavelengths and both instruments have a coefficient of variance $(\mathrm{CV}) \%<3.5 \%$. Again after 5 weeks, samples were taken out, but this time there were no "stress test". The 5 weeks time point for testing was chosen because this is the normal period of time for blood storage, before the membranes of blood cells begin to disintegrate. The leak of hemoglobin into plasma and hemolytic index were thus estimated after the stress test on day 11 and again after 5 weeks of blood storage in the blood bank. 


\section{Statistical analysis}

In the comparative study of the effects of rose hip vs astaxanthin on the facial skin, the magnitude of changes over time (ie, base line to 4-8 weeks) for the same patient was analyzed by one-way analysis of variance (ANOVA). Difference between groups of rose hip powder and astaxanthin was analyzed by Student's $t$-test. This methodology was chosen as the data followed a normal distribution.

In the cell longevity study, the Wilcoxon test for matched pairs was used as the data did not quite follow normal distribution. When comparing the different time points within each group, we used ANOVA. Significance of all values was attained when $P$-value was identical or $<0.05$. $P$-values $>0.05$ and $<0.10$ (borderline significant) are given where as any $P$-value $>0.10$ is given as nonsignificant.

\section{Results}

\section{Blinded study on the skin, wrinkles, moisture content, and elasticity}

Thirty-three subjects completed the blinded study. One subject in the rose hip powder group dropped out because of taking botulinum toxin injection during the study. Baseline demographic analysis of skin condition including Visioscan index indicated a mean depth of Crow's-feet wrinkles for the astaxanthin group of $45.62 \pm 3.99$ vs $45.52 \pm 5.10$ for Hyben Vital, rose hip powder, no statistical significant difference comparing the two groups. Likewise, moisture content of forehead did not show any difference comparing the two groups at the initial level: astaxanthin $52.68 \pm 6.32$ vs Hyben Vital rose hip powder 51.55 \pm 8.94 Corneometer units, no statistically significant difference. When comparing the two groups at the initial level, no statistically significant difference was observed in the skin elasticity (Figures 1-3).

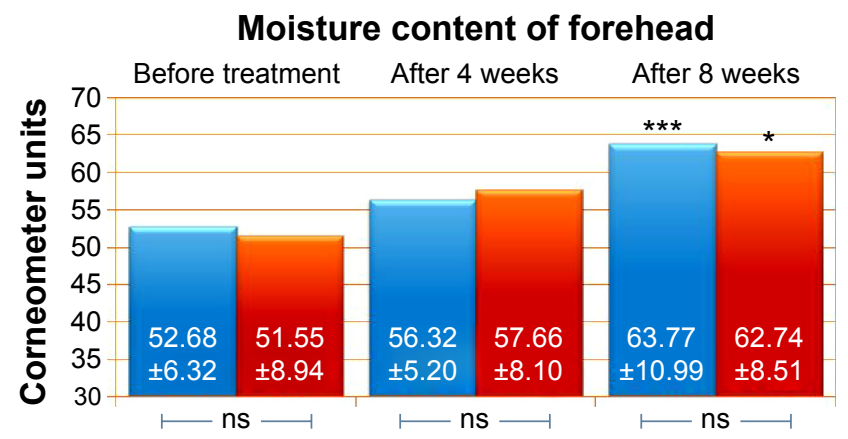

Astaxanthin Hyben Vital $^{\circledR}$ rosehip powder

Figure 2 Moisture content of forehead is given for rose hip powder and for astaxanthin.

Notes: $* * * p<0.00$ I vs before. $* p<0.05$ vs before

Abbreviation: ns, not significant at $P>0.05$.

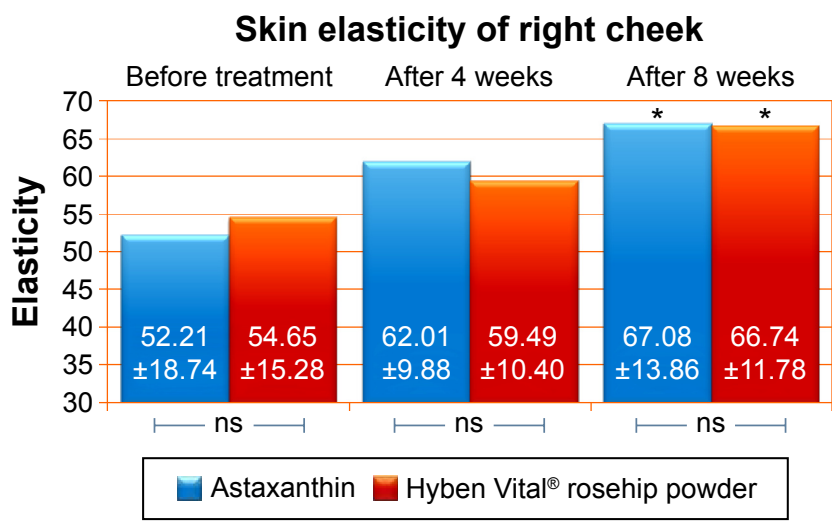

Figure 3 Skin elasticity of right cheek is given for rose hip powder and for astaxanthin.

Note: $* P<0.05$ vs before.

Abbreviation: ns, not significant at $P>0.05$.

Hyben Vital rose hip treatment resulted in a statistically significant reduction in the depths of crow's-feet wrinkles as the initial Visioscan index decreased from $45.52 \pm 5.10$ to $41.78, P<0.05$, after 8 weeks of treatment. As expected, there was a drop in the depth of crow's-feet wrinkels in the group treated with astaxanthin. ${ }^{16}$ The decline was identical to the decline observed for rose hip but was also significant when tested after 4 weeks of treatment. There was no statistically significant difference when comparing the two groups at any time point (Figure 1). Rose hip powder also resulted in a statistically significant increase in the moisture content of the forehead. The initial level rose from $51.55 \pm 8.94$ to $62.74 \pm 8.51$, $P<0.05$ after 8 weeks of treatment. A similar pattern with no differences between the two groups was seen for astaxanthin (Figure 2). Finally, elasticity of the skin was also improved as a result of Hyben Vital treatment as indicated by an initial level of $54.65 \pm 15.28$ which increased to $66.74 \pm 11.78$ after 8 weeks of rose hip treatment, $P<0.05$. A similar improvement was observed for astaxanthin with no significant difference found between the two groups (Figure 3).

Patient's scores on how satisfied they were with their skin after treatments came out positively and without any statistically significant difference comparing groups: rose hip $3.63 \pm 0.81$ vs astaxanthin $4.00 \pm 0.79, P=0.165$. The improvement of the facial skin was visible and significant when blinded researchers evaluated photos taken initially and after 4 weeks and 8 weeks of treatment, with no visible difference between groups, Figure 4A and B.

\section{The evaluation of red cell permeability}

One of the volunteers dropped out before the first blood sample was taken for personal reasons, whereas the rest of the population, 17 volunteers, completed the study. There 
A

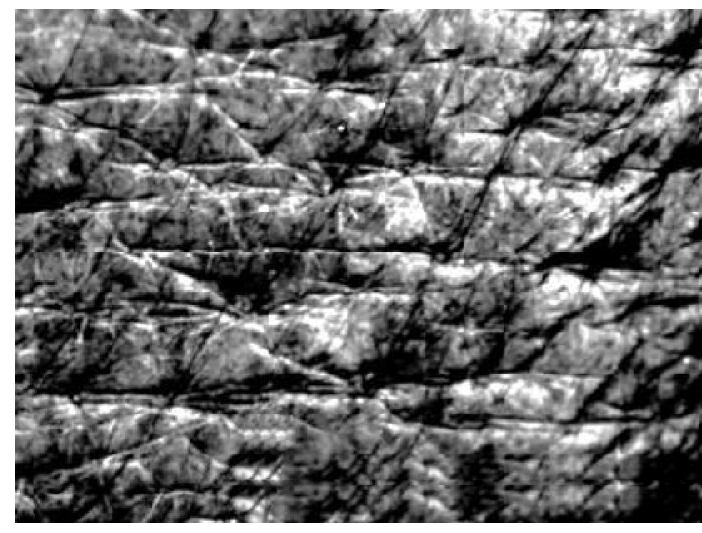

Before

B

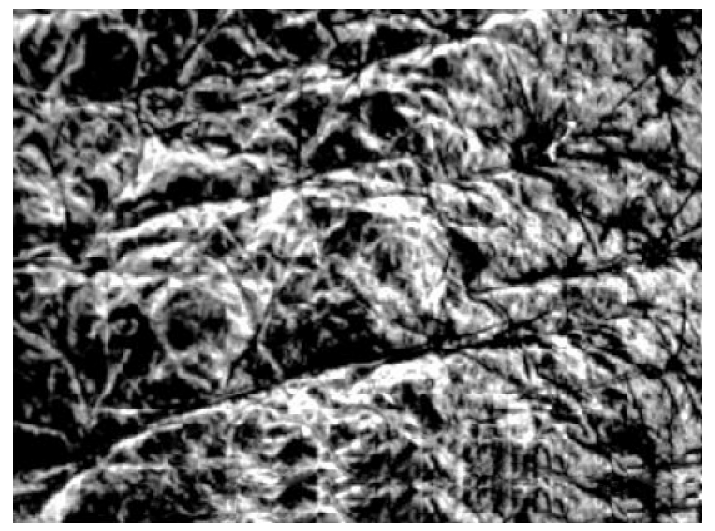

Before

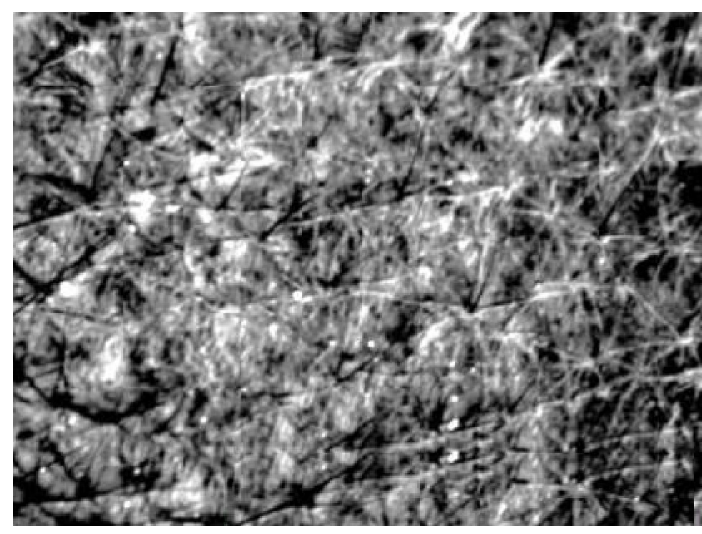

After 8 weeks

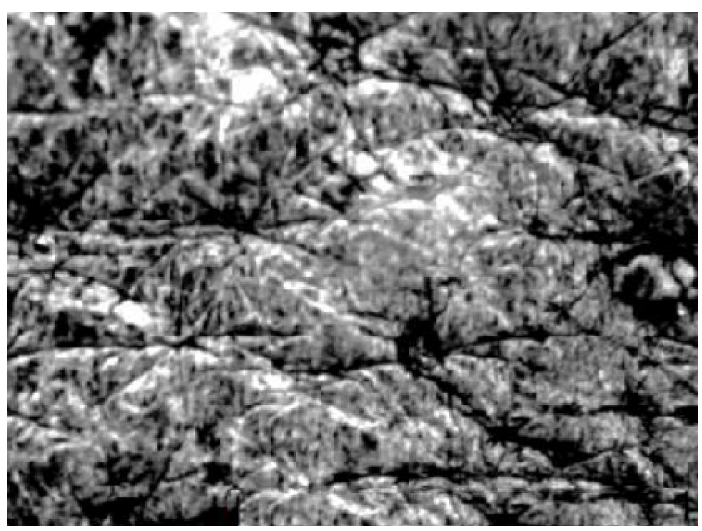

After 8 weeks

Figure 4 Photos of the skin from a volunteer initially and after 8-week treatment with rose hip powder (A) and photos of another volunteer, initially and after 8-week treatment with astaxanthin $(\mathbf{B})$.

was a statistically significant decline in the leak of hemoglobin from red cells as a result of the 28 days of rose hip treatment, when evaluated over the entire period of time. Table 1 shows the ANOVA $P$-values, giving all values after a stress test performed after 11 days $(P<0.05)$, and Table 2 shows all values after 5 weeks storage in a blood bank (0.001). A similar pattern, and also statistical significant, was observed when values were evaluated as hemolytical index, on an alternative equipment, as shown in Table 1 that gives the data obtained after a stress test after 11 days $(P<0.05)$, and Table 2 giving the data obtained after 5 weeks storage in a blood bank $(P<0.05)$. Treatment should be maintained for 21 days before any significant change occurred in the stress test (Table 1), whereas the leak of hemoglobin was significantly lowered after 14 days of treatment when testing cells stored for 5 weeks in the blood bank (Table 2). No change was observed in the control group; data were only available after 14 days, 21 days, and 28 days of the stress test, respectively, due to technical errors. Values for plasma hemoglobin were $11.33 \pm 5.96 \mathrm{mmol} / \mathrm{L}$ vs $11.17 \pm 6.11 \mathrm{mmol} / \mathrm{L}$ vs

Table I Plasma hemoglobin and $\mathrm{H}$-index in red blood cells, before treatment, during a 28 days period of treatment and again after cessation of treatment

\begin{tabular}{llllllll}
\hline & Start & 5 days & I4 days & 2I days & 28 days & 63 days & ANOVA P-value \\
\hline $\begin{array}{l}\text { Plasma Hgb (mmol/L) } \\
\text { II days storage/stress }\end{array}$ & $16.53 \pm 5.35$ & $18.00 \pm 6.73$ & $19.06 \pm 6.1 \mathrm{I}$ & $13.29 \pm 3.84^{\mathrm{a}, \mathrm{b}}$ & $15.00 \pm 5.85^{\mathrm{c}}$ & $17.56 \pm 4.07^{\mathrm{d}}$ & 0.05 \\
$\begin{array}{l}\mathrm{H} \text {-index (arb units) } \\
\text { II days storage/stress }\end{array}$ & $1.24 \pm 0.44$ & $1.24 \pm 0.56$ & $1.4 \mathrm{I} \pm 0.5 \mathrm{I}$ & $0.88 \pm 0.33^{\mathrm{e}, \mathrm{f}}$ & $1.12 \pm 0.49$ & $1.37 \pm 0.50$ & 0.05 \\
\hline
\end{tabular}

Notes: All tests were made after 10 days storage in a blood bank followed by I day of stress test at room temperature. a $P<0.05$ vs start; ${ }^{b P}<0.00$ I vs 14 days; ${ }^{c P}<0.05$ vs start; ${ }^{\mathrm{d} P}<0.055$ vs 28 days; ${ }^{\mathrm{e} P}<0.05$ vs start; $\{$ P $<0.05$ vs 14 days.

Abbreviations: ANOVA, analysis of variance; arb, arbitrary. 
Table 2 Plasma hemoglobin and $\mathrm{H}$-index in red blood cells, before treatment, during a 28 days period of treatment and again after cessation of treatment

\begin{tabular}{llllllll}
\hline & Start & $\mathbf{5}$ days & I4 days & 2I days & 28 days & 63 days & ANOVA P-value \\
\hline $\begin{array}{l}\text { Plasma Hgb (mmol/L) } \\
5 \text { weeks of storage }\end{array}$ & $57.35 \pm 22.84$ & $56.12 \pm 19.24$ & $49.35 \pm 23.0 I^{\mathrm{a}, \mathrm{b}}$ & $52.71 \pm 21.93^{\mathrm{c}}$ & $53.24 \pm 19.60$ & $57.75 \pm 21.44$ & 0.001 \\
$\begin{array}{l}\text { H-index (arb units) } \\
5 \text { weeks of storage }\end{array}$ & $4.82 \pm \mathrm{I} .98$ & $4.82 \pm 1.85$ & $4.06 \pm 2.0 \mathrm{I}^{\mathrm{d}, \mathrm{e}}$ & $4.59 \pm 1.94$ & $4.41 \pm 1.73^{\mathrm{f}}$ & $5.00 \pm 2.07^{\mathrm{g}}$ & 0.05 \\
\hline
\end{tabular}

Notes: All tests were made after 5 weeks storage in a blood bank. ${ }^{a} P<0.00$ I vs start; ${ }^{b} P<0.05$ vs 5 days; ${ }^{c} P<0.05$ vs start; ${ }^{d} P<0.05$ vs start; ${ }^{\text {e }}<0.05$ vs 5 days; ${ }^{\text {}} P<0.09$ vs start; ${ }^{g P}<0.07$ vs 28 days

Abbreviations: ANOVA, analysis of variance; arb, arbitrary.

$11.17 \pm 2.32 \mathrm{mmol} / \mathrm{L}$, respectively $(P<0.99)$, and values for hemolytic index were $0.67 \pm 0.52$ vs $0.67 \pm 0.52$ vs $0.83 \pm 0.41$ arb unit, respectively $(P<0.87)$.

\section{Side effects reported in the study}

In the group of 33 volunteers, one subject in the rose hip powder group experienced nausea that could not be related to rose hip. This patient did not withdraw. No treatment-related side effects were reported in astaxanthin group. No side effects were reported in the 17 volunteers who were tested for red cell membrane permeability during rose hip treatment.

\section{Discussion}

The double-blinded controlled study on the oral supplementation of rose hip powder gave indications of improvements on wrinkles, skin moisture, and elasticity as measured by instrumental assessment at the eighth week, irrespective of the treatment chosen. Comparing the effectiveness between the two treatments, there was no significant difference on the skin improvement effect between rose hip powder and the well-known antiwrinkle and antiphotoaging remedy astaxanthin. ${ }^{16,20}$ However, when evaluated earlier in the trial, after 4 weeks, it seemed as if astaxanthin tended to be a little more powerful, when focusing on crow's-feet wrinkles. However, no significant or borderline significant differences between groups occurred at any time point. Subjective (volunteers) and objective (researchers) evaluation of the skin supported the present findings.

It is interesting to note that astaxanthin, a strong antioxidant from carotenoid pigment and the present rose hip powder also a strong anti-oxidant ${ }^{3}$ and rich in carotenoid pigments, including several xanthins, can inhibit the synthesis of MMP-1, an enzyme responsible for the breakdown of collagen. As both remedies are strong antioxidants, this may help to protect collagen and elastin from free radicals such as reactive oxygen species formed by the process of UV-induced oxidative metabolism responsible for skin aging. ${ }^{3,8,16,20}$ This may to some extent explain the impact on the skin, observed in the present study, as collagen, known as a main component of cartilage in joints also is very central in the skin, and because antioxidants can protect cell membranes also from the damage caused by UV radiation also named photoaging. ${ }^{16,20}$ Another aspect of rose hip impact on the skin is GOPO and its anti-inflammatory properties, ${ }^{7,21}$ indicating an inhibition of human neutrophil chemotaxis and interleukin (IL) production. ${ }^{8,21}$ This antiinflammatory theory can be of particular interest, as UV radiation is known to cause cell damage that induces inflammation and suppress the immune system of the skin. ${ }^{1}$ It is also of interest to note that seeds and seed oil from rose hip for centuries have been used as protection of the skin and also to restore scars after burn injury, especially in South America. ${ }^{4}$ As mentioned earlier, seeds and the oil from rose hip seeds contain high concentrations of PUFA, among them linoleic acid (C18:2n-6) and alpha linolenic acid (C18:3n$3)^{5}$ which are major elements of the PUFA content of the epidermis. ${ }^{6}$ The $n-6$ PUFA have a particular role in structural integrity and barrier function of the skin, and both $n-6$ and $n-3$ PUFA are essential and give rise to potent signal molecules called eicosanoids, which influences the inflammatory response of the skin and can reduce photoaging. The seeds and shells also contain high amounts of carotenoids, which are precursors of vitamin A and high amount of vitamin E. These fat-soluble vitamins are essential in supporting and maintaining the skin. ${ }^{5,22,23}$ Vitamin A stimulates the cells of the skin and has been suggested to restore damaged skin cells and is also reported to be an antiaging ingredient. ${ }^{24}$ In addition, vitamin $\mathrm{E}$ is also reported to support the skin from burns and DNA damage. ${ }^{25}$

Finally, rose hip is also rich in water-soluble vitamin C, polyphenolic compounds, and flavonoids substances, which are reported to have cell supporting properties..$^{26,27}$ There are strong indications for the role of vitamin $\mathrm{C}$ in supporting the skin and collagen formation. ${ }^{28,29}$ There are also indications that vitamin $C$ in combination with vitamin $E$ is superior than being used alone..$^{25,28}$ An integrative action of different substances in rose hip seeds and shells may, therefore, explain the effect of the present rose hip powder supplementation on the skin. 
Cell longevity, when determined as red cell membrane permeability of hemoglobin supported by the measurement of hemolytic index, indicates that the intake of the present rose hip powder reduces the flux of hemoglobin through cell membranes, when exposed to 1 day of stress after 10 days of storage in a blood bank (Table 1). The same came through, when red cells were tested close to the limit of their life length, the time point where cell membranes start to disintegrate - get old, which in our setup was after 5 weeks in the blood bank (Table 2). It is encouraging to note that 2-3 weeks of treatment with a certain food additional can reduce the disintegration of cell membranes, when estimated as the leak of hemoglobin from the interior of the cell into the medium outside the cells, at least when the cells are stored in a blood bank. If cells leak cytosol to their exterior surroundings, it is also likely that external contaminants may leak into the cells interior. If this happens in the epidermis, infection and breakdown of surfaces can occur. Antioxidants, however, has been shown to benefit membranes of red cells, as it was earlier shown that antioxidants can inhibit the damage of red cell membranes in stored blood. ${ }^{13}$ This combined with the fact that rose hip was rated as the strongest antioxidant of all berries ${ }^{3}$ makes it likely that the antioxidant theory can play a role in keeping cell membranes intact. It was also shown in an animal model, that the content of PUFA, C18:2, linoleic acid was improved in red cell membranes after animals were fed high amounts of vegetarian oil with high content of linoleic acid for 15 days and that the red cell membrane stability had improved after the treatment. ${ }^{30}$ This is of particular interest as the present rose hip species has very high seed content of linoleic and also alpha-linolenic acids. It seems likely, therefore, that the present rose hip powder can modify and to some extend diminish the disintegration of red cell membranes and possibly add to red cell membrane longevity by adding to the amount of cell membrane PUFA. The time scale of our cell membrane data, 2-3 weeks treatment before any impact, correlates well with the 15 days mentioned in the above discussed animal study. ${ }^{30}$ A certain galactolipid, GOPO, was recently isolated from the present rose hip species. ${ }^{8}$ The present powdered rose hip as well as the galactolipid GOPO, when isolated, was shown to reduce MMP-1 gene expression. This is interesting as MMP-1 is an enzyme responsible for the breakdown of cell structures such as collagen. Moreover, GOPO and rose hip upregulate genes that are responsible for the synthesis of collagen. ${ }^{8,9}$ In the same study, it was demonstrated that the present rose hip powder had strong anti-inflammatory properties. This notion is supported by clinical studies on patients with joint disease who were given $5 \mathrm{~g}$ of seed and shell containing rose hip powder daily. ${ }^{10,12}$ Different mechanisms may so far explain the observed changes in cell longevity and the supportive impact on the skin.

\section{Strengths and limitations}

It is interesting to note that rose hip powder, containing shells and seeds, seems to modify structures of the skin when given orally and a further improvement of the skin from rose hip might even be available if the intake of the oral preparation was combined with oil from seeds directly added to the surface of the skin. It is also encouraging that there are several explanations for the present findings, as PUFA, especially linoleic acid and alpha-linolenic acid are essential to the skin and very abundant in the present subspecies of rose hip, and in addition, it was shown that certain elements of rose hip including the galactolipid (GOPO) protects collagen from breakdown and may improve its growth. Finally, the antioxidative and anti-inflammatory property of the given powder can protect the skin. The same mechanism may also explain the improved longevity of red cells. Further, it should be noted that although the standardized rose hip powder does indeed contain trace amounts of alkaloids, astaxanthin has not been identified in the pseudo fruits of $R$. canina, to the best of our knowledge. An evaluation of the potential additive effect between pure astaxanthin, a well-known remedy against wrinkles, and the standardized rose hip product (Hyben Vital ${ }^{\mathbb{}}$ ) was not pursued in the current study. This should be investigated in future studies.

With regard to the current study, certain reservations should be taken. A well-powered, large-scale, placebocontrolled follow-up trial on the actual skin conditions is strongly warranted for supporting the present pilot study. The present study on cell longevity should also be repeated and in large-scale placebo-controlled settings. Moreover, future studies should aim to define the more active components of the standardized rose hip product, which may turn out to be GOPO, antioxidants (including the natural xanthines), various small molecules, possibly in concert with PUFA, or other yet unidentified components.

\section{Conclusion}

It is concluded that the present rose hip powder may support the skin and cell longevity by mechanisms involving PUFA, support of collagen, antioxidative, and anti-inflammatory properties.

\section{Acknowledgments}

Hyben Vital is greatly acknowledged for supplying their standardized rose hip powder, Ove Aaskoven, Tolstrup Data, 
for supporting the statistical analysis of the data collected in this study, and Farinaz Raziani for preparing figures.

\section{Disclosure}

$\mathrm{K}$ Wongsuphasawat is a board director for NutraMedica, $\mathrm{K}$ Winther has been a consultant to Hyben Vital on veterinarian products. The authors report no other conflicts of interest in this work.

\section{References}

1. Seis H, Stahl W. Nutritional protection against skin damage from sunlight. Аnпи Rev Nutr. 2004;24:173-200.

2. Pillai $\mathrm{S}$, Oresajo C, Hayward J. Ultraviolet radiation and skin aging: roles of reactive oxygen species, inflammation and protease activation, and strategies for prevention of inflammation-induced matrix degradationa review. Int J Cosmet Sci. 2005;27(1):17-34.

3. Halvorsen BL, Holte K, Myhrstad MCV, et al. A systematic screening of total antioxidants in dietary plants. J Nutr. 2002;132:461-471.

4. Patel S. Rose hips as complementary and alternative medicine: overview of the present status and prospects. Med J Nutrition Metab. 2013;6: 89-97.

5. Fan C, Pacier C, Martirosyan DM. Rose hip (Rosa canina L.): a functional food perspective. Funct Foods Health Dis. 2014;4(11):493-509.

6. Wertz PW. Epidermal lipids. Semin Dermatol. 1992;11:106-113.

7. Öszan M. Nutrient composition of Rosa canina L. Seed and oils. J Med Food. 2002;5(3):137-140. doi:10.1089/10966200260398161.

8. Larsen E, Kharazmi A, Christensen LP, Christensen SB. An antiinflammatory galactolipid from rose hip (Rosa canina) that inhibits chemotaxis of human peripheral blood neutrophils in vitro. J Nat Prod. 2003;66(7): 994-995.

9. Schwager J, Hoeller U, Wolfram S, Richard N. Rose hip and its constituent galactolipids confer cartilage protection by modulating cytokine, and chemokine expression. BMC Complement Altern Med. 2011;11: $105-119$.

10. Warholm O, Skaar S, Hedman E, Mølmen HM, Elk L. The effect of a standardised herbal remedy, made from a subtype of Rosa-canina in patients with osteoarthritis: a double-blind, randomized, placebocontrolled clinical trial. Curr Ther Res Clin Exp. 2003;64(1):21-31.

11. Winther K, Apel K, Thamsborg G. A powder made from seeds and shells of a rose hip subspecies (Rosa canina) reduces symptoms of knee and hip osteoarthritis: a randomized, double-blind, placebo-controlled clinical trial. Scand J Rheumatol. 2005;34(4):302-308.

12. Willich S, Rossnagel K, Roll S, et al. Rose-hip herbal remedy in patients with rheumatoid arthritis - a randomized controlled trial. Phytomedicine. 2010;17(2):87-93.

13. Racek J, Herynkova R, Holecek V, Jerabek Z, Slama V. Influence of antioxidants on the quality of stored blood. Vox Sang. 1997;72:16-19.

14. Fujii T, Saito M. Inhibitory effect of quercitin isolated from rose hip (Rosa canina L.) against melanogenesis by mouse melanoma cells. Biosci Biotechnol Biochem. 2009;73:1989-1993.
15. Fujii T, Ikeda K, Saito M. Inhibitory effect of rose hip (Rosa canina L.) on melanogenesis in mouse melanoma cells and on pigmentation in brown guinea pigs. Biosci Biotechnol Biochem. 2011;75:489-495.

16. Liu X, Shibata T, Hisaka S, Osawa T. Astaxanthin inhibits reactive oxygen species-mediated cellular toxicity in dopaminergic SH-SY5Y cells via mitochondria-targeted protective mechanism. Brain Res. 2009; 1254:18-27.

17. Tominaga K, Hongo N, Karato M, Yamashita E. Cosmetic benefits of astaxanthin on humans subjects. Acta Biochim Pol. 2012;59(1): $43-47$.

18. Moses GC, Lightle GO, Tuckerman JF, Henderson AR. A clinical evaluation of the Cobas FARA clinical chemistry analyser for some routine serum enzymes and glucose. Am J Clin Pathol. 1987;88(5):603-609.

19. Knedel M, Haeckel R, Seidel D, Thiery J, Vonderschmitt DJ, Haenseler E. Analytical performance of the random addess analyser Hitachi 737. A multicenter evaluation. J Clin Chem Clin Biochem. 1986;24(6): 409-432.

20. Yoon HS, Cho HH, Cho S, Lee SR, Shin MH, Chung JH. Supplementating with dietary astaxanthin combined with collagen hydrolysate improves facial elasticity and decreases matrix metalloprotinase- 1 and 12 expression: a comparative study with placebo. J Med Food. 2014; 17(7):810-816.

21. Kharazmi A, Winther K. Rose-hip inhibits chemotaxis and chemiluminescence of human blood neutrophils in vitro and releases certain inflammatory parameters in vivo. Inflammopharmacology. 1999;7(4): 377-386.

22. Brigelius-Flohe R, Traber MG. Vitamin E function and metabolism. FASEB J. 1999;13(10):1145-1155.

23. Ross A. Vitamin A and carotenoids. In: Shils M, Shike M, Ross A, Caballero B, Cousins R, editors. Modern Nutrition in Health and Disease. 10th ed. Baltimore, MD: Lippincott Williams \& Wilkins; 2006:351-375.

24. Mukherjee S, Date A, Patravale V, Korting HC, Roeder A, Weindl G. Retinoids in the treatment of skin aging: an overview of clinical efficacy and safety. Clin Interv Aging. 2006;1(4):327-348.

25. Placek M, Gaube S, Kerkmann U. Ultraviolet B-induced DNA damage in human epidermis is modified by the antioxidants ascorbic acid and D-alphatocopherol. J Invest Dermatol. 1998;124:304-307.

26. Türkben C, Uylaser V, Incedayi B, Celikkol I. Effects of different maturity periods and processes on nutritional components of rose-hip (Rosa canina L.). J Food Agric Environ. 2010;8:26-30.

27. Svoboda A, Psotova J, Walterova D. Natural phenolics in the prevention of UV-induced skin damage. Biomed. 2003;147(2):137-145.

28. Eberling-Konig B, Placzek M, Przybilla B. Protective effect against sunburn of combined systemic ascorbic acid (vitamin C) and d-alphatocopherol (vitamin E). J Am Acad Dermatol. 1998;38:45-48.

29. Ross R, Benditt EP. Wound healing and collagen formation. II. Fine structure in experimental scurvy. J Cell Biol. 1962;12:533-551.

30. Bohles H, Bieber MA, Heird WC. Reversal of experimental essential fatty acid deficiency by cutaneous administration of safflower oil. Am J Clin Nutr. 1976;29:398-401.
Clinical Interventions in Aging

\section{Publish your work in this journal}

Clinical Interventions in Aging is an international, peer-reviewed journal focusing on evidence-based reports on the value or lack thereof of treatments intended to prevent or delay the onset of maladaptive correlates of aging in human beings. This journal is indexed on PubMed Central, MedLine,

\section{Dovepress}

CAS, Scopus and the Elsevier Bibliographic databases. The manuscript management system is completely online and includes a very quick and fair peer-review system, which is all easy to use. Visit http://www.dovepress. com/testimonials.php to read real quotes from published authors. 